\title{
Erratum to: Minimally Invasive Strabismus Surgery
}

\author{
Kenneth W. Wright and Yi Ning J. Strube
}

\section{Erratum to:}

Chapter 22 in K.W. Wright, Y.N.J. Strube, Color Atlas of Strabismus Surgery: Strategies and Techniques,

DOI 10.1007/978-1-4939-1480-7_22

Incorrect figure has been published in Chapter 22, Figure 22.1d on page 188. The following correct figure has been updated:

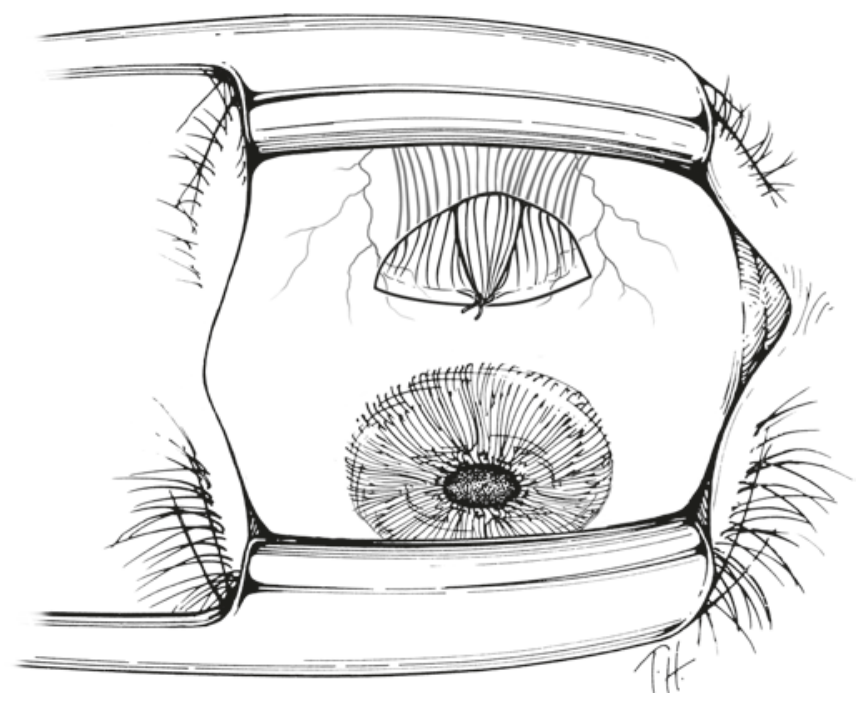

Video links on copyright and chapter opening page of chapter 22 are directed to SpringerLink.com.

Contents on the inside front and back cover were missing and these contents are included now.

The updated online version of the original chapter can be found under DOI 10.1007/978-1-4939-1480-7_22

K.W. Wright, MD

Wright Foundation for Pediatric Ophthalmology and

Adult Strabismus Medical Center, Los Angeles, CA, USA

Y.N.J. Strube, MD, MS, FRCSC, DABO

Queen's University, Kingston, ON, Canada 